\title{
PENAS IBÁÑEZ, A. (2009): CAMBIO SEMÁNTICO Y COMPETENCIA GRAMATICAL. MADRID, IBEROAMERICANA VERVUERT (LINGÜÍSTICA IBEROAMERICANA), 544 PÁGS.
}

\author{
Tomás Albaladejo \\ Universidad Autónoma de Madrid \\ tomas.albaladejo@uam.es
}

En la investigación sobre el lenguaje en su complejidad, y en sus variantes de uso y estilo, así como en su consiguiente multifuncionalidad, desempeñan un papel extraordinariamente fructífero aquellas obras que, sin renunciar a una centralidad -amplia y plural centralidad en el caso de este libro, Cambio semántico y competencia gramatical- sobre la que se articulan, ofrecen una visión y una explicación comprehensivas del objeto de estudio y de la variada problemática de éste. En este libro, la prestigiosa investigadora María Azucena Penas Ibáñez se plantea como objetivo el estudio de los mecanismos de configuración del discurso general y literario, mecanismos que, en su interacción, producen y prolongan sostenidamente una tensión entre el estado que corresponde a su inactividad y el propio de su activación, constituyendo una proyección dinámica sobre la totalidad del lenguaje en el plano del sistema y en el del sintagma, en la langue y en la parole, en el nivel émico y en el nivel ético si tenemos en cuenta la conocida distinción de Kenneth L. Pike. El planteamiento holístico del libro subyace a un desarrollo coherente del tratamiento de sus distintas partes y a la conexión de cada una de ellas con la centralidad a la que antes me he referido.

Se ocupa la autora de la competencia lingüística y literaria contando con su composición gramatical y su realización textual, con un instrumental lingüístico y retórico, con una conexión entre las propuestas históricas y los planteamientos actuales. La dimensión textual y la que denomino 'movilidad semántica' son dos claves en su explicación de lo específico y diferencial del lenguaje literario, de la competencia a él asociada, y le permite acercarse a la cuestión del estilo, a propósito de la cual sitúa su elucidación en el ámbito de 
la sistematicidad de tipos y estructuras, en oposición a la identificación entre estilo y unicidad. Es importante la atención que la autora presta a la connotación como dispositivo de construcción semántica en el lenguaje, tanto en el común como en el literario. La expansión de significado en sentido extra-objetivo, trans-denotativo, que supone la connotación, la sitúa en un lugar privilegiado en el eje poiético-aisthético en el que se proyecta de manera dinámica la creación lingüística y lingüístico-artística en dirección a una interpretación abierta, pero sometida a la regulación de una comprensión que no deja de tener presente la instancia productora o autorial. Paralelamente a esta expansión semántica, la autora estudia las isotopías en la construcción lingüística del texto literario, en la que funcionan como trazadoras de guías de interpretación, como diseñadoras de territorios y de itinerarios interpretativos que, atravesados y seguidos por la instancia receptora, conducen a la reconstrucción, en la interpretación, de la actividad lingüística de la instancia productora. Es así como, con indudable acierto fundamentado en su visión lingüística, pragmática, textual y retórica de la comunicación lingüística y literaria, la autora basa la interpretación en la conexión onomasiológica-semasiológica, en la que se asienta y se proyecta la movilidad semántica.

Sirva de muestra de la complementariedad y de la tensión constructiva de elementos diferentes, diferenciales e incluso opuestos, que tan importante función tienen en la comunicación y en la literatura, el siguiente pasaje del libro: "Los dos tipos de valores semánticos (denotativo y connotativo) no son exclusivos sino complementarios. La lectura paragramática no suprime la lectura lineal, así como tampoco la interpretación metafórica desaloja definitivamente a la interpretación literal. Nada es insignificante en un texto y todo contribuye al despliegue de la polifonía textual" (página 103).

Una gran parte del libro está dedicada a las figuras retóricas, que María Azucena Penas estudia partiendo de la estructuración explicativa de éstas debida a la Rhétorique générale del Groupe $\mu$, el grupo de investigadores de la Universidad de Lieja que en 1970 llevó a cabo una reinterpretación del sistema retórico que, junto con la Nouvelle rhétorique de Chaïm Perelman y Lucie Olbrechts-Tyteca, con la Retórica General Textual de Antonio García Berrio, con la Retórica Pragmática de Antonio López Eire y con el cognitivismo figural de Stefano Arduini, representa una auténtica renovación de los estudios retóricos en la segunda mitad del siglo XX. La que desde hace años vengo denominando 'Rhetorica recepta' es la retórica que, configurada fundamentalmente por las aportaciones de Aristóteles, de Cicerón, de la anónima Rhetorica ad Herennium y de Quintiliano, ha sido recibida, interpretada y desarrollada por las sucesivas generaciones que han venido después de los "Rhetores Latini maiores" y han 
contribuido a la renovación de la retórica que ha tenido lugar con diferentes grados de intensidad pero de manera continuada a lo largo de la historia, hasta las más recientes contribuciones hechas a su estudio. Es una renovación en la que se mantienen las líneas maestras de la explicación del hecho retórico y del texto o discurso retórico en él incluido, instauradas en la 'Rhetorica recepta'; la persistencia del sistema retórico da coherencia a las distintas interpretaciones de aquélla. En tal sentido, la autora de Cambio semántico y competencia gramatical es consciente de la validez de la quadripertita ratio, que en la Institutio oratoria de Quintiliano supone la elevación del conjunto de las cuatro operaciones-adiectio, detractio, transmutatio e inmutatio- que subyacen en las figuras y los tropos (en combinación con la distinción "in uerbis coniunctis" / "in uerbis singulis") y las explican, a mecanismo categorial compuesto que está presente en otras muchas operaciones lingüísticas, semióticas, comunicativas y, en definitiva, retóricas. María Azucena Penas despliega un muy amplio conjunto de conocimientos lingüísticos y retóricos en el estudio que en sucesivos capítulos del libro hace de los metaplasmos, las metataxis, los metalogismos y los metasememas, estudio en el que atiende plenamente a la gramática y a la retórica, que para Quintiliano atañen, respectivamente, al hablar correctamente y al hablar con eficacia comunicativa, con finalidad persuasiva. Apoyada en el cognitivismo retórico de Stefano Arduini, la autora despliega una defensa de la figura como vía y construcción de conocimiento alejada de la idea de desvío, en coherencia con la defensa del cuestionamiento de la consideración del lenguaje literario (y retórico) como simple desviación del uso normal del lenguaje. La constante perspectiva semántica que mantiene la autora en sus planteamientos tiene un rendimiento inigualable en el estudio de los tropos y de las figuras de carácter semántico. La movilidad semántica presente como concepto axial en el libro es clave para su explicación de la funcionalidad figural en lo específico del lenguaje literario.

Su explicación de las metáboles, de los dispositivos de modificación retórica, manifiesta un conocimiento extenso y detallado de la creatividad figural y de sus raíces en el lenguaje con una proyección estilística y estética en el lenguaje literario y en el discurso expresivo, provisto de eficacia comunicativa precisamente por su construcción lingüística y por su posicionamiento pragmático en lo que son las bases retóricas del lenguaje, las cuales sostienen la naturaleza retórica del lenguaje, que con tanto acierto ha explicado Antonio López Eire, es decir, su retoricidad, su inherente condición retórica.

La naturaleza retórica del lenguaje está presente a lo largo del libro, por la preparación retórica de la autora, que, consciente de la complejidad del lenguaje y de dicha naturaleza, no sólo no renuncia a la utilidad descriptiva, analítica y 
explicativa que ofrece la retórica para el estudio del lenguaje y de la comunicación, sino que la adopta como uno de los componentes nucleares del instrumental compuesto teórico-crítico y teórico-práctico del libro. Esta atención a la condición retórica del lenguaje y, consiguientemente, a la utilización del instrumental que con más eficacia puede dar cuenta de ella llevan a la autora a hacer una explicación conjunta de los fenómenos lingüístico-gramaticales de carácter general, como la polisemia, y de los fenómenos estrictamente retóricos y literarios, como las figuras y los tropos. Las implicaciones lingüísticas generales y retóricas de unos y otros fenómenos avalan la perspectiva por ella adoptada.

Como ciencia del discurso, la retórica, en las partes artis u operaciones retóricas y en una visión global del hecho retórico, en el que tan importantes son nociones como ethos, pathos, res, uerba, aptum, taedium o kairós, tiene una configuración semiótica en la que están presentes los aspectos sintácticos, los aspectos semántico-extensionales o referenciales y los aspectos pragmáticos del discurso y de su comunicación. Cambio semántico y competencia gramatical, sin perder su fundamentación retórica, cuenta con la tripartición semiótica como perspectiva de estudio de la realidad lingüística en tanto en cuanto es realidad sígnica. El planteamiento semiótico que de modo explícito adopta la autora en los últimos capítulos del libro y que está presente, en muchos casos de modo implícito en los capítulos anteriores, tiene una intensa proyección pragmática, como no podía ser de otra manera en una obra sustentada en gran medida por la retórica como es este libro. Como pone de manifiesto el tratamiento de la euidentia que María Azucena Penas hace, la pragmática atraviesa los distintos niveles del discurso, correspondientes a las partes artis, en ninguna de las cuales deja de estar presente la atención a la instancia receptora por parte de la instancia productora. Por otra parte, la atención prestada por la autora a la relación de texto y contexto se conecta perfectamente con el aptum como adecuación entre todos los componentes del hecho retórico y del discurso retórico y, por extensión, del hecho comunicativo y literario y de la obra literaria.

María Azucena Penas ofrece en este libro una amplia visión, con la consiguiente explicación, del lenguaje común y del lenguaje literario y de la problemática de la constitución de éste en relación con aquél. El libro es también una demostración del interés que ofrece la utilización de un instrumental compuesto en el que la retórica desempeña un papel de guía, estructuración e interpretación en una dirección estilística y persuasiva de diversos componentes de otras ciencias del lenguaje y de la comunicación.

El libro de María Azucena Penas se sitúa en una de las líneas más fructíferas de los modernos estudios lingüísticos y literarios, la del estudio del lenguaje literario, que tantos y tan importantes frutos ha dado en España, donde destaca 
la Poética lingüística planteada por Antonio García Berrio, y en otros países europeos como Alemania, Austria, Rusia, Francia e Italia, más que en los Estados Unidos de América, donde el hecho de que en su historia de los estudios lingüísticos en el siglo XX triunfara la tendencia representada por Leonard Bloomfield frente a la representada por Edward Sapir, hizo que el estudio del lenguaje literario no adquiriera un desarrollo equivalente al europeo. Cambio semántico y competencia gramatical es un libro que viene a continuar esa línea en un momento en el que en los estudios literarios, tal vez como reacción a la intensidad y exhaustividad con las que en ellos se ha investigado sobre el lenguaje literario, especialmente en las décadas de los 60, los 70, los 80 e incluso los 90 del siglo XX, han surgido planteamientos que han ido dejando de lado el estudio de aquél. Sin embargo, a pesar de la importancia, el acierto y el interés del tratamiento del lenguaje en los estudios literarios y a pesar del gran número de contribuciones que se han ocupado del lenguaje literario, estoy convencido de que hay que continuar estudiándolo, por su condición de objeto difícilmente abarcable en su totalidad, en todos y cada uno de sus aspectos, y por la necesidad de ensayar nuevas propuestas metodológicas para su estudio, y es en esta actitud de mantenimiento de la conciencia de la necesidad de continuar el estudio del lenguaje literario, del uso artístico del lenguaje, donde es de justicia destacar la plena validez de este libro de María Azucena Penas, que, con su publicación, ofrece a la investigación en los estudios lingüísticos y literarios una contribución imprescindible para el tratamiento del lenguaje literario, contando con los fundamentos e instrumentos de la retórica y con la comparación con el lenguaje común. 